\title{
¿Qué he aprendido de Marx y qué es lo que sigue vigente?
}

Recibido: 20/04/2021
Aprobado: 30/06/2021
Publicado: 31/07/2021
ADAM PRZEWORSKI New York University (NYU) ap3@nyu.edu

\section{RESUMEN}

¿Debería leerse a Marx hoy? ¿Cuáles de sus teorías sobreviven al paso del tiempo y cuáles deberían abandonarse? Este artículo revisa cuatro de los temas de Marx: la búsqueda de la abundancia material, la compatibilidad entre capitalismo y democracia, el papel del Estado y la teoría de la dinámica del capitalismo.

Palabras clave: Teoría marxista, capitalismo y democracia, socialdemocracia

\section{What have I learned from Marx and what remain valid?}

\begin{abstract}
Should one read Marx today? Which of his theories survive the test of time and which should be abandoned? This article reviews four of Marx's topics: the quest for material abundance, the compatibility of capitalism and democracy, the role of the state, and the theory of the dynamics of capitalism.
\end{abstract}

Keywords: Marxist theory, capitalism and democracy, social democracy

1 Este artículo fue publicado en inglés por la revista Politics and Society en su versión online el 16 de setiembre del 2020. El autor autoriza la publicación de su artículo traducido al español en esta revista. Así mismo, el autor agradece por sus comentarios a Pierre Birnbaum, Martin Castillo, Zhiyuan Cui, Joanne Fox-Przeworski, Alex Hicks, Fernando Limongi, Jose María Maravall, David Plotke, Molly Przeworski, John Roemer, Ignacio Sanchez-Cuenca, y Jerzy J. Wiatr. A Alberto Gonzales-Zúñiga Guzmán y Guillermo Rochabrún por la traducción y la revisión de la traducción, respectivamente. 
| e vez en cuando me preguntan si "todavía" soy marxista. No sé si alguna vez lo fui: nunca creí en la teoría de la historia de Marx, en ningún tipo de inevitabilidad o en la promesa del comunismo. Pero durante la mayor parte de mi vida me sentí atraído por algunas de las intuiciones y análisis de Marx.

Si fui marxista, siempre fui un marxista analítico, mucho antes de que se acuñara la etiqueta de "marxismo analítico". Me influyó profundamente la confrontación intelectual entre marxismo y positivismo que estalló en Polonia en 1957, justo cuando ingresé al Departamento de Filosofía y Sociología de la Universidad de Varsovia como estudiante. Antes de la Segunda Guerra Mundial, Polonia tenía dos fuertes tradiciones intelectuales en las ciencias sociales. Una era el positivismo lógico. La otra era una tradición historicista, predominantemente idealista alemana. Después de la guerra, aunque el marxismo se convirtió en una obvia nueva influencia, el positivismo mantuvo una fuerte presencia. Se produjo un debate en la revista Pensamiento Filosófico (Myśl filozoficzna) entre marxistas y positivistas, que los marxistas estaban perdiendo, pero en 1948 el debate se resolvió mediante "medidas administrativas". La revista se cerró y los positivistas fueron expulsados de la universidad. El Departamento de Filosofía de la Universidad de Varsovia fue reemplazado por "Materialismo dialéctico" y el Departamento de Sociología por "Materialismo histórico". Pero con el fin del estalinismo la represión cedió, el Departamento de Filosofía y Sociología se abrió en 1957 y resurgió el mismo debate. Fue un debate excelente, llevado a cabo en un clima de verdadera apertura intelectual, y resultó ser excepcionalmente fecundo hasta la ola represiva de 1968, que obligó al exilio a varios de sus participantes. Fue una experiencia única dentro del bloque soviético de la época.

Los interlocutores en estos debates fueron filósofos y sociólogos. ${ }^{2}$ Los filósofos marxistas fueron dirigidos por Adam Schaff, un epistemólogo que trabajaba en la relación entre lenguaje y pensamiento, pero que también introdujo en Polonia al "joven Marx" de los Manuscritos económico-filosóficos de 1844 y polemizó con los existencialistas franceses. ${ }^{3}$ Los historiadores marxistas de la filosofía incluían a Bronisław Baczko y Leszek Kołakowski. Entre los historiadores marxistas de la filosofía estaban Bronislaw Baczko y Leszeck Kolakowski. ${ }^{4}$ El lado no marxista estaba dominado intelectualmente

4 Baczko participó en el debate inicial con una salva, en 1951, contra el principal lógico de la época, Tadeusz Kotarbiński, pero se volvió profundamente escéptico, tal vez desilusionado, cuando fue mi maestro en 1958. Yo me encontraba muy influenciado por su apasionada combinación de compromiso y escepticismo, 
por los sociólogos Stanisław Ossowski y María Ossowska. ${ }^{5}$ Stefan Nowak, alumno de Ossowski, era un metodólogo que realizó el primer estudio de encuesta en la Polonia de posguerra. ${ }^{6}$ Un metodólogo de la historia influyente fue Andrzej Malewski. ${ }^{7} \mathrm{Y}$ el ancla del enfoque positivista fue un lógico de mayor edad y de renombre mundial, Kazimierz Ajdukiewicz. ${ }^{8}$

Si uno quiere rastrear el origen del "marxismo analítico", está en la Polonia luego de 1957. Los atacantes eran positivistas que preguntaban a los marxistas: ¿Por qué creen que la historia sigue ciertas leyes? ¿Qué quieren decir con "intereses de largo plazo"? ¿Son las clases la única fuente de estratificación social? ¿Por qué las clases irían tras intereses de largo plazo? Y habiendo perdido la mayor parte de la protección política, los marxistas tuvieron que valerse por sí mismos, encontrando respuestas a tales preguntas. El líder programático de este propósito fue Julian Hochfeld, ${ }^{9}$ cuyo seminario en sociología de las relaciones políticas fue el foro para lo que defendió como "marxismo abierto". Los participantes incluyeron a Zygmunt Bauman, Włodzimierz Wesołowski, Jerzy J. Wiatr, ${ }^{10}$ y otros a quienes ya no recuer-

y escribí mi tesis de maestría bajo su dirección. Se hizo conocido internacionalmente por su trabajo sobre la Revolución francesa y sobre Rousseau (Baczko 1994, 2001). Kołakowski no necesita presentación, pero debe destacarse que, como Baczko, se desplazó desde el estalinismo. Cuando tomé un curso con él, estaba trabajando sobre el positivismo y publicó ese trabajo por primera vez en inglés como The Alienation of Reason: A History of Positivist Thought (1966), y más tarde como Positivist Philosophy from Hume to the Vienna Circle (1972).

5 El libro de Stanisław Ossowski de 1957, publicado en castellano como Estructura de clases y conciencia social (1972), planteó un gran desafío para los marxistas al argumentar que las posiciones objetivas de clase pueden no reflejarse en la identificación de clase subjetiva. El trabajo más conocido de María Ossowski incluye Moralność mieszczańska de 1956, publicado en inglés como Bourgeois Morality (1986), y Socjologia moralności: zarys zagadnień de 1963, publicado en inglés como Social Determinants of Moral Ideas (1971).

6 Fue el primer sociólogo polaco en publicar en una revista estadounidense (Nowak 1960). Para su homenaje a Ossowski, véase Nowak (1974).

7 Malewski falleció en 1963, habiendo sido coautor, con Jerzy Topolski, de Studia z metologii historii [Estudios en metodología de la historia] (1960).

8 Ajdukiewicz obtuvo reconocimiento internacional por sus artículos publicados ya en la década de 1920. Un resumen de sus puntos de vista maduros se publicó como Problems and Theories of Philosophy (1975). [Una versión portuguesa se publicó como Problemas e Teorias da Filosofia (1979)]. Hice su curso de dos años de lógica matemática, que me preparó para aprender nuevos desarrollos metodológicos a lo largo de toda mi vida.

9 En 1963 se publicó una colección de sus artículos en polaco: Studia o marksowskiej teorii spoleczeństwa [Estudios sobre la teoría marxista de la sociedad] (1963). Hochfeld también editó una revista, Studia Socjologiczno-Polityczne.

10 Bauman (1966) escribió un homenaje a Hochfeld. A pesar de su tono polémico, su libro de 1961 Z zagadnień współczesnej socjologii amerykańskiej (Bauman 1962) abrió la puerta a su influencia en Przeworski. Bauman también fue influyente al presentar a Polonia a Antonio Gramsci, sobre quien reflexionó en 2001: "Gramsci, paradójicamente, me protegió de convertirme en antimarxista, lo que les sucedió a muchos otros estudiosos decepcionados, que con un gesto rechazaron lo que en el pensamiento de Marx era entonces, y sigue siendo, valioso" (Bauman y Tester 2001, 26). Wesołowski fue la figura central en los debates sobre la estratificación social, con un libro publicado en polaco en 1964 y publicado en inglés como Classes, 
do. Yo era el más joven, y nunca hablé, pero seguía los debates con la boca abierta.

Teniendo en cuenta estos antecedentes, era natural que pasase a ser un ávido participante del proyecto intelectual lanzado a fines de la década de 1970 por G. A. Cohen y Jon Elster: un intento sistemático de aclarar qué seguiría siendo válido acerca de las teorías de Marx si estuvieran sujetas a criterios científicos estándar. Por entonces el marxismo althusseriano desarrolló la buena estratagema de tener su propia epistemología, su propia forma de evaluar la validez de su teoría. Rompimos con este enfoque y dijimos: "No, tienes que evaluar al marxismo de la misma manera que cualquier otra teoría. O es coherente o es incoherente, es verdadero o falso". Me uní al grupo de marxismo analítico en 1979 o 1980; creo que ese fue el segundo año del grupo. Produjimos algunas obras importantes que han perdurado, incluidos el compendio Analytical Marxism de John Roemer, Making Sense of Marx de Jon Elster, Karl Marx's Theory of History de G. A. Cohen, General Theory of Exploitation and Class de Roemer, y mi Capitalism and Social Democracy. ${ }^{11}$ Dejé el grupo en 1995 porque llegué a la conclusión de que habíamos cumplido con nuestra tarea. En ese momento llegué a creer que la teoría económica marxista no tenía sentido, que la teoría de Marx del conflicto de clases se basaba en supuestos incorrectos y que cualquier teoría de la historia requiere microfundamentos. También llegué a la conclusión de que no existe un "marxismo" único, no todo lo que Marx (y Engels) escribieron pertenece a un cuerpo unificado de teoría, pero que, sí, los escritos de Marx contienen varias teorías seminales de fenómenos particulares.

Huelga decir que no llegué aisladamente a estas conclusiones. Aprendí mucho de mis compañeros de viaje intelectuales, siendo los más importantes Jon Elster, John Roemer, Michael Wallerstein y Erik Olin Wright. También creo que debo ubicarme políticamente. En algunas reuniones del Grupo de Septiembre nos clasificábamos a lo largo del eje dizquierda-derecha, y mis colegas siempre me ubicaron dentro del grupo en la derecha. Esto se debió a que siempre valoré la libertad y me preocupé menos por la igualdad. Mi fijación por Marx tuvo su origen en los Manuscritos económico-filosóficos, el

Strata and Power (RLE Social Theory) (1979). Wiatr era el más cercano a un científico político que a un sociólogo en este grupo. Llevó a cabo un estudio pionero de las elecciones de 1957 en Polonia, publicado en inglés como "Elections and Voting Behavior in Poland" (en Ranney 1961). No lo conocía bien en ese momento, pero me convertí en su asistente en la Academia de Ciencias de Polonia en 1964, y mantuvimos una amistad de por vida.

11 [Las versiones en español pueden encontrarse en las referencias bibliográficas. $N$. del E.]. 
“joven Marx”. Además, siempre leo a Marx como un teórico causal, no como un teórico ético: en algún lugar de los Grundrisse dice que un "precio justo" es como un "logaritmo amarillo". ${ }^{12}$ Por lo tanto, nunca me dejé llevar por la búsqueda que hacían algunos de mis amigos de una teoría marxista de la justicia. Me consideraba un verdadero izquierdista, comprometido con el proyecto político de emancipación universal de la necesidad económica. A su vez, vi la obsesión por la igualdad (y el empleo) como una consecuencia del compromiso socialdemócrata de la izquierda institucional. Sin embargo, me preocupaba la política práctica, lo que significaba que era pragmático, y analizaba la política en términos estratégicos más que normativos. Por último, era un internacionalista. Había vivido durante períodos prolongados en cuatro países y no tenía instintos ni lealtades nacionalistas. Yo creía, para citar a un líder sindical de Chicago Steel Workers, Ed Sadlowski, al comentar sobre el auge de Solidaridad en Polonia en 1980, que "el trabajador se pone los pantalones de la misma manera aquí y allá y se jode de la misma manera aquí y allá".

Entonces, ¿qué papel jugaron los escritos de Marx (y Engels) en mi desarrollo intelectual? Como dije, lo que originalmente me atrajo de Marx fue la pregunta que planteó en sus primeros escritos: a saber, cómo sería la vida si las personas se liberaran de tener que fatigarse para sobrevivir, si las necesidades materiales básicas de todos estuvieran satisfechas, si fueran libres de ir tras cualquier otra cosa que quisieran; en el ejemplo de Marx, pescar por la mañana y resolver ecuaciones matemáticas por la tarde. Era una utopía, pero que abría los ojos. Me impulsó a leer con avidez a los freudianos sociales, hasta casi reprobar en el programa de posgrado de la Northwestern University, porque algunos profesores pensaban que esas preocupaciones no tenían cabida en un departamento de ciencia política. Pero entonces los azares de la historia me llevaron a Chile, en el momento en que la cuestión intelectual fundamental era la compatibilidad del capitalismo y la democracia, y la cuestión política práctica era si el socialismo podía alcanzarse por medios democráticos. Estos dos temas formarían a partir de entonces mi agenda intelectual. Y allí encontré inspiración en los análisis políticos de Marx de los eventos en Francia entre 1848 y 1851: los leí y releí, los enseñé y los examiné por escrito. Mi interés por Marx me llevó a impartir un curso titulado "Teoría Marxista del Estado", que posteriormente cambió su título a "Teorías del Estado" (que fue el origen de The State and the Economy under Capitalism); y luego la "Introduction

12 Los detalles de la publicación de todas las obras de Karl Marx a las que se hace referencia se pueden encontrar al final de este artículo. 
to Political Economy" (conferencias publicadas como States and Markets). ${ }^{13}$ Finalmente, para entender a Marx en términos causales, traté de encontrar microfundamentos a sus teorías, lo que me llevó a interpretaciones de sus análisis basados en la teoría de juegos. La aplicación de este aparato metodológico demostró que a menudo se equivocaba en sus conclusiones, pero también que las preguntas que hacía eran fundamentales.

En las páginas siguientes desarrollaré estos cuatro temas: la búsqueda de la abundancia material, la compatibilidad del capitalismo y la democracia, el papel del Estado en el capitalismo y el individualismo metodológico.

\section{Libertad de la necesidad}

El punto de partida de Marx en los Manuscritos económico-filosóficos es que llegará un momento en que será posible satisfacer las necesidades materiales básicas de todos sin que las personas tengan que "esforzarse", realizar un trabajo que personalmente les resulta insatisfactorio. Como dijo Marx mucho después, "el reino de la libertad solo comienza allí donde cesa el trabajo determinado por la necesidad y la adecuación a finalidades exteriores" ( $E l$ capital, vol. III, 1044). Es posible que esa posibilidad no se realice cuando llegue a ser factible, pero es factible, y los obstáculos para alcanzarla no son tecnológicos sino sociales: residen en la organización social de la producción y el intercambio.

Este texto no envejeció bien. Al releerlo, por primera vez en casi sesenta años, lo encontré en gran parte repleto de romanticismo del siglo XIX, argumentos que son solo juegos de palabras y contradicciones. Para ser justos, mis comentarios sobre el mismo adolecen de igual romanticismo (Przeworski 1986). Pero abre dos líneas de investigación: ¿Cuáles son, para las formas en que las personas experimentan su existencia, las consecuencias de la escasez material, incluida la necesidad de realizar un trabajo desagradable? ¿Qué querría la gente y qué estaría haciendo si estuviera libre de las limitaciones materiales? Ambas preguntas son reveladoras.

La principal respuesta de Marx a la primera pregunta es que cuando la gente experimenta escasez material "Su trabajo no es, así, voluntario, sino forzado, trabajo forzado. Por eso no es la satisfacción de una necesidad,

13 Véase Przeworski (1970, 1986). 
sino solamente un medio para satisfacer las necesidades fuera del trabajo" (Manuscritos, 109). En términos más generales, "La vida misma aparece solo como medio de vida" (Manuscritos, 111). Nos vemos obligados a realizar actividades y relaciones sociales que no satisfacen por sí mismas nuestras necesidades, pero que son necesarias para perpetuar nuestra existencia. Esto es lo que Marx quiso decir con "alienación". Incluso si la pasión de alguien es tocar el violín, a menos que sea el único entre un millón que sea capaz de sobrevivir satisfaciendo esa necesidad, debe hacer otras cosas: "exprimirse", solo para sobrevivir. El dinero es un medio de intercambio universal: todas las relaciones sociales están mediadas por el dinero. Incluso el sexo se puede obtener por dinero. Incluso "invertimos" en nuestros hijos, los disciplinamos y capacitamos para que puedan ganar dinero, para que puedan sobrevivir. Dada la escasez, la necesidad de sobrevivir organiza todas las relaciones sociales, incluida la forma en que las personas conviven y procrean.

Marcuse (1965) reconoció que alguna represión, en el sentido freudiano de este término, siempre era necesaria para que las sociedades puedan satisfacer las necesidades materiales. El alcance de esta "represión necesaria" depende del nivel de desarrollo de nuestra capacidad productiva. Sin embargo, pensó que gran parte de la represión, particularmente en las sociedades económicamente desarrolladas, llega mucho más allá del nivel mínimo necesario; es "sobrante". Por tanto, somos menos libres de lo que podríamos ser. Su proyecto consistía entonces en diferenciar la represión necesaria, de todas las restricciones a la libertad individual que, dada nuestra capacidad productiva, no son requeridas por nuestras necesidades materiales. Obviamente, la distinción entre represión "necesaria" y "superflua" supone que las necesidades materiales pueden ser saciadas; es decir, que el valor que damos a la satisfacción de otras necesidades aumenta a medida que se satisfacen las necesidades materiales. Esta suposición subyace en la opinión actual de que hemos entrado en una era de "posmaterialismo", y puede ser cierto o no. Pero el proyecto filosófico de Marcuse ha sido lastimosamente abandonado.

El análisis de Marcuse se vuelve particularmente fructífero cuando empezamos a pensar en el "desempleo". Algunas personas no encuentran empleo porque nuestra tecnología es tal que el nivel máximo de producción que se puede alcanzar, dado el capital actual, no requiere que todos tengan un empleo remunerado. A su vez, nuestras sociedades están organizadas de tal manera que estar desempleado es una calamidad. Un aspecto de la miseria del desempleo es que el ocio es caro: los desempleados no tienen medios 
para disfrutar como deseen de su tiempo libre. Dada esta estructura, cuando los partidos obreros se vieron obligados a abandonar el proyecto de socialización de los medios de producción, se obsesionaron con brindar "pleno empleo". Pero, ¿por qué se debería obligar a la gente a trabajar duro cuando no es necesario? Como proclamaba un antiguo eslogan de IBM, "Las máquinas deberían funcionar, la gente debería pensar". La solución de Marx, ya en los Manuscritos económico-filosóficos, fue reducir el tiempo de trabajo de todos, liberar a todos del trabajo en la medida de lo posible. De hecho, el tiempo de trabajo se ha reducido en los últimos cien años; sin embargo, dada la distribución del trabajo, el desempleo sigue siendo endémico en las sociedades económicamente avanzadas. Y la razón por la que el trabajo no se distribuye equitativamente, y alguna fracción siempre esté desempleada, es que el espectro de perder el trabajo es necesario para inducir la disciplina laboral entre los que están empleados (Shapiro y Stiglitz 1986).

Los "freudianos sociales" también siguen a Marx (y al Engels tardío) al enfocar la organización social de la sexualidad en condiciones de escasez material; es decir, en la relación de formas de convivencia y propiedad. Ven a la familia, y la represión sexual que esta organización social impone, como un medio para preservar la propiedad. Las personas no son libres para satisfacer sus necesidades sexuales de la forma que mutuamente deseen. Se ven obligados a ingresar en la institución del matrimonio para poder compartir propiedades o incluso solo un seguro médico. Marcuse admite nuevamente que cierta represión sexual puede ser necesaria para permitir la satisfacción de las necesidades materiales, pero sostiene que la represión de la libertad sexual va mucho más allá de lo necesario.

A la segunda pregunta, ¿qué querría y haría la gente si estuviera libre de escasez y trabajo?, Marx responde que no puede ser respondida. Rechaza la opinión de que hay algo ahistórico que constituye la "naturaleza humana". Piensa que las personas buscarían la "autorrealización", pero no es que podamos decir qué la encontrarán: algunos pueden avocarse a la resolución de ecuaciones, otros pueden ir tras sus inquietudes artísticas, o jugar ajedrez, mientras que otros simplemente querrán ver crecer los árboles. Su utopía es una sociedad en la que las personas son libres de hacer lo que les parezca para realizarse: lo que significa que diferentes personas pueden querer hacer cosas diferentes. La noción de "igualdad" no tendría sentido, porque las necesidades no serían conmensurables: como lo vio Heller (1978), alguien sería rico cuando tenga necesidades ricas. 
El fin de la escasez no es un patrón para alcanzar la felicidad. Alguien que quiere ser músico puede no tener talento para ello, y puede sufrir por no ser capaz de lograrlo. Además, sin un medio de intercambio universal, todos los valores son autónomos:

[...] solo se puede intercambiar amor por amor, confianza por confianza, etc. Si se quiere gozar del arte hasta ser un hombre artísticamente educado; si se quiere ejercer influjo sobre otro hombre, hay que ser un hombre que actúe sobre los otros de modo realmente estimulante y alentador. Cada una de las relaciones con el hombre - y con la naturaleza - ha de ser una exteriorización determinada de la vida individual real que se corresponda con el objeto de la voluntad. Si amas sin despertar amor; esto es, si tu amor en cuanto amor no produce amor recíproco, si mediante una exteriorización vital como hombre amante no te conviertes en hombre amado, tu amor es impotente, una desgracia (Manuscritos, 81).

De hecho, algunos social freudianos, en particular Brown (1959), pensaron que la libertad de las necesidades materiales haría que las personas se desesperaran al confrontarlas directamente con la conciencia de que somos mortales. La utopía de Marx no es un reino de felicidad sino de libertad, sea lo que esta genere.

Los primeros escritos de Marx y Marcuse desempeñaron un papel importante en la revolución cultural de las décadas de 1960 y 1970, pero ahora están casi olvidados.

\section{Capitalismo y democracia}

\section{Dinámica del régimen}

Imaginemos una población que consta de tres tipos de sujetos: trabajadores, burguesía y militares. Todos buscan maximizar sus ingresos, los cuales ellos consumen. Los trabajadores son mayoría. El orden establecido es un sistema político en el que los ingresos de los trabajadores son más bajos que el promedio, mientras que los ingresos de la burguesía son más altos. Supongamos ahora que si los trabajadores obtuvieran el sufragio, lo usarían para generar una igualdad completa, de modo que todos recibieran el mismo ingreso promedio. Para evitar este resultado, la burguesía puede ofrecer a los militares una transferencia de cierta magnitud para reprimir a los trabajadores y man- 
tener bajos los salarios, con algún costo para los militares. Por lo tanto, la burguesía haría una oferta a los militares siempre que sus ingresos fueran aún más altos que el promedio, y los militares lo aceptarían si esta transferencia fuera mayor que su costo de reprimir a los trabajadores. La burguesía hace entonces esta oferta si la desigualdad de ingresos es alta y si reprimir a los trabajadores no es demasiado costoso.

Este, en pocas palabras, es el relato que hace Marx de la Francia de 18481851. Los trabajadores conquistaron el sufragio, y una manifestación masiva a favor de salarios más altos asustó a la burguesía para que se volviera en busca de protección a Luis Napoleón. Este ganó las elecciones con el apoyo de los campesinos, hizo un autogolpe y reprimió a los trabajadores.

Ante la amenaza de estos, la burguesía entendió que "[...] para mantener intacto su poder social, su poder político debe ser quebrantado; que los individuaos burgueses pueden seguir explotando a otras clases [...] bajo la condición de que su clase sea condenada junto con las otras clases a la misma nulidad política; que para salvar su bolsa, hay que renunciar a la corona, y que la espada que había de protegerla tiene que pender al mismo tiempo sobre su propia cabeza como la espada de Damocles" (18 brumario, 56-57).

Marx también considera, aunque rechazándola como "pequeño burguesa", el compromiso de clase, en el que los trabajadores reducirían sus demandas salariales y la burguesía preferiría convivir con ellas en lugar de buscar protección de los militares:

El carácter peculiar de la socialdemocracia consiste en exigir instituciones democrático-republicanas, no para abolir a la par los dos extremos, capital y trabajo asalariado, sino para atenuar su antítesis y convertirla en armonía (18 brumario, 42).

Por lo tanto, los trabajadores tienen dos estrategias para elegir: la revolucionaria (aumentar el costo de la represión para los militares) y la socialdemócrata (restringir sus demandas salariales).

Casi toda la problemática de la dinámica del régimen está aquí. De hecho, la mayor parte de la literatura sobre las transiciones de régimen consiste en resolver diferentes variantes de este modelo, examinando cómo la desigualdad económica afecta las posibilidades de que un país se vuelva democrático y de 
que la democracia sobreviva. ${ }^{14} \mathrm{El}$ análisis de Marx fue fundamental, y como marco sigue en pie.

\section{Capitalismo y democracia}

La conclusión que Marx extrae de los acontecimientos en Francia es este comentario sobre la "constitución burguesa":

[...] mediante el sufragio universal, otorga la posesión del poder político a las clases cuya esclavitud social debe eternizar: al proletariado, a los campesinos, a los pequeñoburgueses. Y a la clase cuyo viejo poder social sanciona, a la burguesía, la priva de las garantías políticas de este poder. Encierra su dominación política en el marco de unas condiciones democráticas que en todo momento son un factor para la victoria de las clases enemigas y ponen en peligro los fundamentos mismos de la sociedad burguesa. Exige de los unos que no avancen, pasando de la emancipación política a la social; y de los otros que no retrocedan, pasando de la restauración social a la política (Las luchas de clases en Francia, 82-83).

La combinación de democracia y capitalismo es, por tanto, una forma inherentemente inestable de organización de la sociedad, "la república no significa en general más que la forma política de la subversión de la sociedad burguesa y no su forma conservadora de vida" (18 brumario, 20. [en cursivas en el original]), “...solo un estado excepcional y espasmódico de cosas [...] imposible como forma normal de sociedad" (Writings on the Paris Commune, 198).

Donde Marx se equivocó fue respecto a la estructura del conflicto entre trabajadores y capitalistas, la que vio como un juego de suma cero: salarios y ganancias: "[S]e hallan en relación inversa. La parte de la que se apropia el capital — la ganancia — aumenta en la misma proporción en que disminuye la parte que le toca al trabajo —el salario-, y viceversa" (Trabajo asalariado $y$ capital, t. 1, 85). Esto es obviamente cierto en el margen, pero luego Marx da un salto fatal:

[...] incluso la situación más favorable para la clase obrera, el incremento más rápido posible del capital, por mucho que mejore la vida material del obrero, no suprime el antagonismo entre sus intereses y los intereses del burgués [...].

14 Véase Acemoglu y Robinson (2006), o Boix (2003). 
Ganancia y salario seguirán hallándose, exactamente lo mismo que antes, en razón inversa (Trabajo asalariado y capital, t. 1, 86).

Si la burguesía invierte y la economía crece, hay ganancias conjuntas que explotar: tanto las ganancias como los salarios pueden aumentar. Los trabajadores pueden intercambiar los salarios actuales por el empleo y el consumo futuros. No es de extrañar, entonces, que la visión de Marx sobre la incompatibilidad del capitalismo y la democracia resultara ser falsa. En algunos países - específicamente trece- la democracia y el capitalismo coexistieron sin interrupciones durante al menos un siglo, y en muchos otros países durante períodos más cortos, pero no obstante prolongados, la mayoría de los cuales continúan hasta hoy. Los partidos de la clase trabajadora que esperaban abolir la propiedad privada de los recursos productivos se dieron cuenta de que este objetivo era inviable; aprendieron a valorar la democracia y a administrar las economías capitalistas cada vez que las elecciones los llevaron al poder. Los sindicatos, también considerados originalmente como una amenaza mortal para el capitalismo, aprendieron a moderar sus demandas. El resultado fue un compromiso, el "estado de bienestar keynesiano": los partidos de la clase trabajadora y los sindicatos consintieron en el capitalismo, mientras que los partidos políticos burgueses y las organizaciones de empleadores aceptaron alguna redistribución de la renta. Los Gobiernos aprendieron a gestionar este compromiso: regular las condiciones laborales, desarrollar programas de seguridad social e igualar las oportunidades, al mismo tiempo de promover la inversión y contrarrestar los ciclos económicos. Sin embargo, el compromiso fue tenue. Se derrumbó bajo la ofensiva neoliberal de la década de 1980, con consecuencias que aún están por verse. ${ }^{15}$

\section{Desigualdad económica y política}

Es interesante que, en un texto escrito en 1844, Marx ofreció una razón por la cual la igualdad de derechos políticos puede no ser una amenaza mortal para la propiedad:

El Estado suprime a su modo las diferencias de nacimiento, estamento, cultura, ocupación, declarándolas apolíticas, proclamando por igual a cada miembro del pueblo partícipe de la soberanía popular, sin atender a esas diferencias, tratando

15 Véase Przeworski (2019). [Una entrevista de Luis Tonelli al autor sobre este libro se encuentra en https:// bit.ly/3y8YHDI. N. del E.]. 
todos los elementos de la vida real del pueblo desde el punto de vista del Estado. No obstante el Estado deja que la propiedad privada, la cultura, las ocupaciones actúen a su modo y hagan valer su ser específico ("Sobre la cuestión judía").

Cuando ingresan al ámbito de la política como ciudadanos, los individuos se vuelven anónimos. Como ciudadanos no son ricos o pobres, blancos o negros, educados o analfabetos, hombres o mujeres. No tienen cualidades. Pero esto no significa que repentinamete se hayan vuelto iguales. Como individuos, siguen siendo ricos o pobres, educados o no. Siguen estando provistos de recursos desiguales. Y estos recursos son importantes por la influencia que pueden y de hecho ejercen sobre las políticas de los Gobiernos. La democracia es un sistema universalista, un juego con reglas abstractas e imparciales. Pero los recursos que los diferentes grupos aportan a este juego son desiguales. Consideremos un partido de baloncesto jugado entre personas que miden dos metros y medio, y personas bajas como yo. El resultado es claro. Cuando los grupos compiten por la influencia política, el poder económico se transforma en poder político, y a su vez el poder político se convierte en un instrumento para el poder económico. Organizados en sindicatos integradores y centralizados, aliados con partidos políticos, los asalariados pueden poner en acción su propia musculatura política, como en Escandinavia. Pero el campo de juego político es desigual en cualquier sociedad económicamente desigual.

La riqueza o los ingresos afectan la influencia política a través de varios canales, con efectos más fuertes o más débiles sobre la desigualdad política. Consideremos simplemente dos mecanismos: i) incluso teniendo los mismos derechos, algunas personas no disfrutan de las condiciones materiales necesarias para participar en la política; y ii) la competencia entre grupos de interés por la influencia política lleva a los decisores de políticas a favorecer a los contribuyentes más grandes. En primer lugar, la desigualdad política puede surgir en sociedades económicamente desiguales sin que nadie haga nada para aumentar su influencia ni reducir la influencia de otros; simplemente porque algunas personas no gozan de las condiciones materiales necesarias para ejercer sus derechos políticos.

Los derechos para actuar carecen de contenido cuando faltan las condiciones propicias, por lo que la desigualdad de estas condiciones es suficiente para generar una influencia política desigual. En segundo lugar, el dinero se puede utilizar para influir en los resultados de las elecciones, o para influir en las políticas gubernamentales una vez dados los resultados de estas. Si bien los políticos 
y los burócratas pueden tener diversas motivaciones, el hecho ineludible es que la política cuesta dinero. Por lo tanto, incluso si todo lo que quieren es ganar las elecciones, los políticos pueden estar dispuestos a vender su influencia política (Grossman y Helpman 2001). Y debido a que las personas con altos ingresos tienen más que perder con la redistribución, de lo que las personas con bajos ingresos obtienen de ella, los ricos gastan más dinero en la política.

La igualdad política efectiva no es posible en sociedades social y económicamente desiguales. La igualdad económica no se puede lograr en sociedades políticamente desiguales. Este es un círculo vicioso. El hecho evidente es que la democracia no es eficaz para reducir la desigualdad.

\section{El Estado}

La frase a menudo citada de Marx sobre el Estado en el Manifiesto comunista dice así: "El poder estatal moderno es solo un comité que administra los asuntos comunes de toda la clase burguesa" (cap. 1). Las preguntas obvias son: ¿cuáles son los "asuntos comunes de toda la clase burguesa” y por qué el Estado los manejaría? Esta indicación reaparece en varios otros textos donde Marx repite versiones de esta formulación, agregando "contra los abusos tanto de los capitalistas individuales como de los trabajadores". Esta complicación dio lugar a debates intensos y excepcionalmente fructíferos a finales de los sesenta y principios de los setenta.

Marx subraya repetidamente que tanto los capitalistas como los trabajadores compiten entre sí. En nuestro lenguaje contemporáneo, ambos están comprometidos en el dilema del prisionero, buscando sus intereses individuales frente al interés común. Tanto los capitalistas como los trabajadores juegan a dos niveles: uno contra el otro, y contra la otra clase. En esa medida, el interés común de toda la burguesía es contener el peligro que presenta la clase trabajadora, que amenaza tanto las ganancias como el capitalismo.

Los debates sobre la teoría marxista del Estado que se iniciaron con una polémica entre Ralph Miliband y Nicos Poulantzas, en 1969, ampliaron radicalmente la lista de problemas que enfrentaba la burguesía. ${ }^{16}$ Para entender por qué, debemos regresar. En la teoría de Marx del desarrollo del capitalismo (regresaré sobre esto más adelante), las relaciones capitalistas de producción

16 Véase Miliband $(1990,1991)$ y Poulantzas $(1978,1990)$. 
se reproducen automáticamente, por la mera repetición de actos de producción: "El proceso capitalista de producción, pues, reproduce por su propio desenvolvimiento la escisión entre fuerza de trabajo y condiciones de trabajo" (El capital, t. I, 711). Aunque supuestamente Marx tuvo la intención de escribir en algún momento un cuarto volumen de El capital, dedicado al Estado, no hay nada que pudiera haber escrito. Según la teoría en los tres volúmenes que sí escribió, el Estado no juega ningún papel en la reproducción del capitalismo. Este supuesto se volvió visiblemente insostenible a medida que el capitalismo atravesaba crisis fiscales, crisis de "desmercantilización" y crisis de legitimación (O’Connor 1981, Offe 1985, Habermas 1989). La teoría que surgió de esos debates, en distintas variantes, sostenía que las condiciones necesarias para que el capitalismo sobreviva no las crea espontáneamente el capitalismo como sistema de producción e intercambio, de modo que si el capitalismo va a permanecer, el Estado debe generar activamente tales condiciones. El papel del Estado consiste en llenar los "vacíos funcionales" del capitalismo.

Pero, ¿por qué el Estado, cubierto por personas seleccionadas mediante elecciones democráticas, incluidas muchas de la izquierda política, manejaría los asuntos comunes de la burguesía contra los asedios de capitalistas individuales, así como de trabajadores organizados? Una respuesta fue que el Estado casi siempre está saturado de "hombres provenientes del mundo de los negocios y la propiedad, o de la clase media profesional" (Miliband 1991, 66). Esta es una respuesta débil, tanto desde el punto de vista empírico como teórico. Otra respuesta, de la que reclamo coautoría es la "dependencia estructural del Estado respecto del capital" (Przeworski y Wallerstein 1988). Dado que las decisiones de inversión privada determinan las posibilidades futuras de consumo y empleo, incluso los Gobiernos pro-laboristas deben anticipar las reacciones de los posibles inversores y empleadores a todas sus decisiones. Si bien estas restricciones dejan espacio para elegir políticas particulares, no pueden ir demasiado lejos, poniendo en riesgo la rentabilidad. Pero ninguna de estas respuestas fue dada por Marx, y ninguna es específicamente "marxista": la primera es compartida por las teorías de la "élite del poder" y la segunda por la economía política neoclásica (Barro 1993; Bertola 1993, 1996).

\section{Métodos}




\section{El individualismo metodológico}

Marx siempre interpreta las preferencias individuales desde las posiciones que las personas ocupan en la estructura económica de la sociedad: "Pero aquí solo se trata de personas en la medida en que son la personificación de categorías económicas, portadores de determinadas relaciones e intereses de clase" (El capital, vol. I, Prefacio a la edición de 1867 [cursivas en el original]). Y considera únicamente aquellos objetivos que deben buscar como tales. Si los capitalistas no maximizaran las ganancias, serían eliminados por la competencia en el mercado. Como individuos, los capitalistas pueden ser buenos padres, pueden incluso ser revolucionarios (Engels), pero deben maximizar las ganancias; de lo contrario, no seguirán siendo capitalistas. Por lo tanto, a cada instante, quienes sobrevivieron como capitalistas fueron solo aquellos que maximizaron las ganancias, una suposición compartida por los economistas, al menos desde Alchian (1950).

Los capitalistas no pueden equivocarse acerca de sus intereses - si lo hacen, desaparecen como capitalistas - , pero los miembros de otras clases sí pueden. Esto es cierto para los trabajadores, cuyo interés "objetivo" "a largo plazo" es abolir el capitalismo, pero que pueden no saberlo; pueden tener "falsa conciencia". Lo mismo ocurre con los artesanos, comerciantes o artesanos autónomos, la "pequeña burguesía", así como con los campesinos. En los análisis históricos, Marx identifica las inclinaciones de todos ellos a partir de sus ideas y acciones; de modo que, por ejemplo, los campesinos ven a Luis Napoleón como su libertador. Pero en la teoría más esquemática de la historia solo admite dos clases, capitalistas y trabajadores, e imputa a estos guiarse por sus intereses objetivos. "La pregunta no es que este o aquel proletario, o incluso todo el proletariado, en este momento considere cuál es su objetivo. La pregunta es qué es [...] lo que se verá obligado a hacer" (La sagrada familia, 53). "No se trata de lo que este o aquel proletario, o incluso el proletariado en su conjunto, pueda representarse de vez en cuando como meta. Se trata de lo que el proletariado es y de lo que está obligado históricamente a hacer, con arreglo a ese ser suyo" (La sagrada familia, 102).

Obviamente, los trabajadores enfrentan un problema de acción colectiva: compiten entre sí por el empleo. Tienen que organizarse para actuar como una colectividad: la "clase en sí" debe transformarse en "clase para sí":

Las condiciones económicas primero transformaron a las masas del país en trabajadores [...] esta masa es, pues, ya una clase frente al capital, pero aún no para 
sí misma. En la lucha esta masa se une y se constituye en una clase para sí. Los intereses que defiende se convierten en intereses de clase. Pero la lucha de clase contra otra clase es una lucha política (Miseria de la filosofía, 295-296).

Organizar a los trabajadores en un actor colectivo es la misión del partido, cuyo papel, como lo identifica Marx en el Manifiesto comunista, es "convertir al proletariado en una clase". Nótese que su formulación del problema de la acción colectiva no es la que da Olson (1992): los trabajadores no organizan un partido; más bien, el partido organiza a los trabajadores. Sin embargo, los numerosos intentos de Marx de explicar por qué los trabajadores se unirían para luchar contra el capitalismo siguen siendo puramente exhortaciones. Sucederá en algún momento en el futuro porque debe suceder.

La paradoja central de la teoría de la historia de Marx es que la muerte del capitalismo es una consecuencia necesaria de las leyes de su desarrollo y, sin embargo, requiere una acción revolucionaria de la clase trabajadora. Es una paradoja porque o la muerte del capitalismo es inevitable independientemente de las acciones de esta clase, y entonces ella no tiene ningún papel que desempeñar, o puede ocurrir solo como resultado de una revolución, y luego depende de su acción.

\section{La dinámica del capitalismo}

Resumiendo en 1859 sus puntos de vista, Marx escribió:

En un estadio determinado de su desarrollo, las fuerzas productivas materiales de la sociedad entran en contradicción con las relaciones de producción existentes o - lo cual solo constituye una expresión jurídica de lo mismo- con las relaciones de producción dentro de las cuales se habían estado moviendo hasta ese momento. Esas relaciones se transforman de formas de desarrollo de las fuerzas productivas en ataduras de las mismas. Se inicia entonces una época de revolución social. [...] Una formación social jamás perece hasta tanto no se hayan desarrollado todas las fuerzas productivas para las cuales resulta ampliamente suficiente, y jamás ocupan su lugar relaciones de producción nuevas y superiores antes de que las condiciones de existencia de las mismas no hayan sido incubadas en el seno de la propia antigua sociedad (Contribución a la crítica de la economía política, 4-5). 
Esta es la historia trabajando como un reloj: un sistema institucional funciona exitosamente mientras una mano se apoye detrás de la otra, y se transforma cuando las dos manos coinciden, ni un minuto antes o después. Pero los relojes societales solo pueden funcionar si alguien empuja las manecillas; como dice Roemer (1986), incluso si los teoremas de las ciencias sociales se refieren a cambios a nivel macro, sus demostraciones deben explicar cómo se generan tales cambios.

¿Por qué, entonces, el capitalismo debe ser reemplazado por otra forma de organización social? Para responder a esta pregunta, el lector debe entrar en el peculiar esquema contable de Marx. En su terminología, el capital tiene dos partes: constante (fijo) + variable (trabajo). Viene entonces el supuesto crucial: solo el trabajo genera excedente. Por tanto, plusvalor $=$ capital variable, ${ }^{17}$ y la producción total es: capital constante + capital variable + excedente. Constantes y variables son insumos que se reproducen en cada ciclo de producción; el excedente es la producción por encima de los costos de reproducción. Ahora consideremos lo que sucede en este esquema contable con la tasa de ganancia, definida como excedente/capital total. Cuando el capital constante es 200 y el capital variable es 100, la tasa de ganancia es 100/(200+ $100)=0.33$. Cuando el capital constante pasa a ser 500 , permaneciendo igual el capital variable, la tasa de ganancia desciende a 100/(500 + 100) $=0.166$. Cuanto mayor sea el capital constante, dado el capital variable, menor será la tasa de ganancia.

El progreso tecnológico consiste enteramente de una mayor productividad laboral. Y a medida que se utiliza más capital fijo por trabajador, ${ }^{18} \mathrm{el}$ volumen de producción aumenta, pero la tasa de ganancia cae: "El crecimiento gradual del capital constante en relación con el capital variable conduce necesariamente a una caída gradual de la tasa general de ganancia" (El capital, t. III, cap. XIII). Por lo tanto, a medida que pasa el tiempo, el sistema capitalista debe llegar a un estado en el que la tasa de ganancia sea cero: nadie querrá invertir y nadie querrá producir. El sistema debe morir. Hay un momento óptimo para cambiar las instituciones, y los agentes del cambio, los capitalistas, quieren cambiarlas en ese momento. El capitalismo contiene una "contradic-

17 [Esta igualdad conduce a una tasa de plusvalor $(p / v \times 100)$ de $100 \%$. La tasa de ganancia que se ejemplifica a continuación se basa en esta proporción. Pero la relación cuantitativa entre $p$ y $v$ no tiene por qué ser esta. Se trata solamente de un ejemplo numérico entre muchos otros igualmente posibles. De todos modos, la exposición de Przeworski no depende de esta circunstancia. N. del E.].

18 [Przeworski dice "capital fijo", el cual es conceptualmente muy distinto del "capital constante". Este último es el término pertinente, como se puede ver en la cita de Marx en los renglones siguientes. $N$. del E.]. 
ción": su desarrollo conduce necesariamente a su muerte. (Téngase en cuenta que Keynes y Schumpeter pensaron lo mismo, pero por diferentes razones).

¿Ocurre este resultado porque los capitalistas son miopes y no ven que al invertir en capital fijo derribarán el sistema? La respuesta de Marx es que los capitalistas deben competir entre sí:

[...] un capitalista que dispone de un capital grande obtiene una masa mayor de ganancia que un pequeño capitalista que perciba ganancias aparentemente altas [...]. Cuando el capitalista más grande quiere hacerse un hueco en el mercado, utiliza [los ingresos] de manera práctica, es decir, deliberadamente baja su tasa de ganancia para empujar al pequeño contra la pared. El capitalista que emplea métodos de producción perfeccionados pero aún no generalizados, vende por debajo del precio comercial, pero por encima de su precio individual de producción (El capital, t. III, cap. XIII).

Por tanto, los capitalistas se ven atrapados en el dilema del prisionero: si uno no invierte, los que lo hacen lo expulsarán del mercado; si todos lo hacen, la tasa promedio de ganancia disminuirá.

Las pérdidas son inevitables para la clase en su conjunto. Pero, ¿qué parte de ellas tiene que soportar cada capitalista? Esto lo decide la fuerza y la astucia; al llegar aquí, la concurrencia se convierte en una lucha entre hermanos enemigos. A partir de este momento se impone el antagonismo entre el interés de cada capitalista individual y el de la clase capitalista en su conjunto (El capital, t. III, cap. XIII).

Es notable que los trabajadores no desempeñen ningún papel en el desarrollo o la caída del capitalismo. Pueden acelerar la caída organizándose, pero el capitalismo caerá tarde o temprano, hagan lo que hagan (El capital, vol. II, cap. X).

En síntesis, la teoría de Marx afirma que el sistema capitalista debe marchitarse debido al proceso dinámico que él mismo genera. Tal como la entiendo, esta es la primera teoría dinámica del cambio institucional endógeno, que apenas ha sido superada en la actualidad. ${ }^{19}$ Los supuestos, en particular que el progreso técnico siempre ahorra trabajo, son erróneos y llevan a conclusiones incorrectas. Más aun, a la luz de la teoría moderna de los juegos dinámicos, es necesario preguntarse por qué los capitalistas no se confabulan para escapar de las garras del dilema del prisionero. Pero esto es mucho menos mecánico

19 Véase Galor (2011) y Lagerlof (2002). 
que algunos libros recientes que llevan el mismo título. De hecho, el desarrollo del capitalismo sigue siendo poco conocido.

\section{Haciendo un balance}

Con frecuencia las intuiciones de Marx son potentes, pero algunos de sus análisis son erróneos, algunos correctos pero superados, algunos seminales pero aún insuficientemente explorados, y algunos abandonados. Poca gente lee a Marx en estos días. ¿Deberían hacerlo?

La pregunta va más allá de Marx. Los científicos sociales profesionales no leen casi nada que se haya escrito más de unos cuantos años atrás. De hecho, leer artículos que ya están publicados significa que uno está detrás de la frontera del conocimiento. Si las ciencias sociales son verdaderamente acumulativas, entonces leer "los clásicos" es solo una pérdida de tiempo: todo lo que dijeron está contenido y superado por los escritos más recientes. Pero en las fronteras del conocimiento hacemos pequeñas preguntas: modificamos los supuestos, o volvemos a poner a prueba teorías comúnmente compartidas con mejores datos. Solo cuando aparecen anomalías importantes comenzamos a preguntarnos qué salió mal, a repensar todo el "paradigma". Aquí es cuando volvemos a las grandes preguntas, antes de que se hubieran introducido todos los matices y sutilezas.

Para traer esta excursión abstracta en la filosofía de la ciencia de regreso a Marx, consideremos nuevamente la desigualdad económica. Estudiamos con avidez los efectos de diversas políticas en la distribución del ingreso, solo para descubrir que algunas de ellas son más o menos efectivas, pero que nunca aportan mucho. ¿Por qué? Creo que la principal razón para volver hoy a Marx es su insistencia en la importancia de la estructura de la propiedad en la configuración de la distribución del ingreso. Aunque los socialistas aprendieron a convivir con el capitalismo, y aunque en algunos países han tenido un éxito razonable en mitigar la desigualdad de ingresos y generar crecimiento, el proyecto político de imponer tributos y proporcionar servicios sociales llegó a su límite en la década de 1970. En Suecia, donde se originó todo el proyecto y donde estaba más avanzado, los socialdemócratas intentaron extenderlo en la década de 1970 dando a los trabajadores una voz en la organización de la producción ("codeterminación") e introduciendo cierta propiedad pública de las empresas ("fondos de ganancia de los salarios"), pero ninguna 
de las reformas fue muy lejos..$^{20}$ La ley newtoniana del capitalismo es que la desigualdad aumenta constantemente a menos que su aumento sea contrarrestado por acciones recurrentes y vigorosas de los Gobiernos. El proyecto socialdemócrata iba a alimentar las causas de la desigualdad y contrarrestar sus efectos, y perdió fuerza.

No estoy argumentando contra la asignación de recursos por parte del mercado: con todas sus ineficiencias, los mercados son el mecanismo de asignación de recursos más conocido que conocemos. A donde Marx nos dirige es a repensar la estructura de propiedad y la correspondiente distribución de poder dentro de las empresas. Las discusiones sobre el "socialismo de mercado" surgen de vez en cuando, cada vez que el proyecto socialdemócrata fracasa (Ward 1957, Nove 1998[1983], Elster y Ove 1993[1989]). La pregunta es si las empresas con diferentes estructuras de propiedad (propiedad de los empleados, propiedad parcial de los empleados, propiedad pública, propiedad del Estado), que están expuestas a restricciones competitivas, generarían mayores ingresos y más satisfacción laboral, y si una combinación de tales formas de propiedad generaría un mayor bienestar social que las empresas privadas. No pretendo tener las respuestas, pero comparto la convicción de Roemer (2020) de que es sobre esto que deberíamos estar pensando. Aumentar los impuestos sobre los altos ingresos o la riqueza, para redistribuir o apoyar los servicios públicos, es atractivo y debería ser fácil en un país tan desigual como Estados Unidos: un impuesto del $2 \%$ sobre las grandes fortunas financiaría mucho de lo que mucha gente necesita con urgencia. Pero la mitigación no es transformación, y sin transformar las relaciones de propiedad, la necesidad de mitigar la desigualdad es eterna.

Ahora que he dado mi razón para leer a Marx, me doy cuenta de que no todo el mundo lo lee de la misma manera. Algunos ignoran su materialismo. Recientemente, la "dominación" se ha tornado en cultural, casi completamente abstraída de sus bases materiales, y expandida a todas las relaciones sociales. La dominación de las mujeres se manifiesta en que se les paga menos que a los hombres cuando realizan los mismos trabajos, pero no en las muchas mujeres que ganan un salario mínimo mientras que las ejecutivas ganan 300 veces más. No soy marxista hasta el punto de creer que el género y otras formas de discriminación sean causadas solo por el capitalismo. Son "excesos", en el lenguaje de Marcuse. Pero ignorar las relaciones económicas deforma

20 Véase Pontusson (1994). 
nuestra perspectiva. Para Marx, los dominados comían pan; en el "marxismo cultural" de hoy, se alimentan de "dignidad". Sin embargo, no se puede comer dignidad y la gente tiene que comer para actuar.

[...] debemos comenzar señalando que la primera premisa de toda existencia humana y también, por tanto, de toda historia, es que los hombres se hallen, para "hacer historia", en condiciones de poder vivir. Ahora bien, para vivir hace falta comer, beber, alojarse bajo un techo, vestirse y algunas cosas más [...]. Por consiguiente, lo primero, en toda concepción histórica [...] es observar este hecho fundamental en toda su significación y en todo su alcance, y colocarlo en el lugar que le corresponde (La ideología alemana, 28).

Este tema nos remite a los puntos de vista de Marx sobre la relación entre las condiciones materiales y la conciencia, sobre la que a veces fue bastante sutil, pero a veces totalmente mecánico. No entro en este tema porque todo lo que Marx tenía que decir fue superado por Gramsci (1999), quien creo que lo hizo bien. ${ }^{21}$ Desafortunadamente, el "marxismo cultural" hace lo mismo con Gramsci que con Marx, ignorando su insistencia en que cualquier ideología, para ser eficaz en la orientación de las acciones de las personas, debe estar fundamentada en las condiciones materiales, en la "experiencia vivida". La lección de Marx es que cualquier análisis de la vida bajo el capitalismo debe partir de las condiciones materiales. El aporte de Gramsci es que no debe terminar ahí, pero requiere comenzar allí. Por eso, algo de lo que pasa estos días con la izquierda me llena de horror. 


\section{Referencias bibliográficas}

Acemoglu, D. y Robinson, J. 2006. Economic Origins of Dictatorship and Democracy. Nueva York: Cambridge University Press.

Ajdukiewicz, K. 1975. Problems and Theories of Philosophy. Cambridge: Cambridge University Press.

Ajdukiewicz, K. 1979. Problemas e Teorias da Filosofia. Sao Paulo: Livraria Editora Ciencias Humanas.

Alchian, A. 1950. Uncertainty, Evolution, and Economic Theory. Journal of Political Economy, (58), 211-22.

Baczko, B. 1994. Ending the Terror: The French Revolution after Robespierre. Cambridge, París: Cambridge University Press, Editions de la maison des sciences de l'homme.

Baczko, B. 2001. Lumieres de l'utopie. París: Payot.

Barro, R. 1990. Gasto del gobierno en un modelo simple de crecimiento endógeno. Journal of Political Economy, (98), S103-S126.

Bauman, Z. 1966. In Memory of Julian Hochfeld (1911-1966). Polish Sociological Bulletin, (14), 5-7.

Bauman, Z. 1962. Z zagadnień współczesnej socjologii amerykańskiej. Warszawa: Książka i Wiedza.

Bauman, Z. y Tester, K. 2001. Conversation I. En Conversations with Zygmunt Bauman. Londres: Polity.

Bertola, G. 1993. Factor Shares and Savings in Endogenous Growth. American Economic Review, 83 (5), 1184-1198.

Bertola, G. 1996. Factor Shares in OLG Models of Growth. European Economic Review, 40 (8), 1541-1560.

Boix, C. 2003. Democracy and Redistribution. Nueva York: Cambridge University Press.

Brown, N. 1959. Life Against Death: The Psychoanalytical Meaning of History. Nueva York: Vintage Books.

Cohen, G. A. 1986. La teoría de la historia de Karl Marx: una defensa. Madrid: Siglo XXI Editores.

Elster, J. 1985. Making Sense of Marx. Studies in Marxism and Social Theory. Nueva York: Cambridge University Press.

Elster, J. y Moene, K. (Eds.). 1993. Alternativas al capitalismo. Madrid: Ministerio de Empleo y Seguridad Social.

Galor, O. 2011. Unified Growth Theory. Princeton, Nueva Jersey: Princeton University Press.

Gramsci, A. 1999. Cuadernos de la cárcel. Ciudad de México: Ediciones Era. 
Grossman, G. y Helpman, E. 2001. Special Interest Politics. Cambridge: MIT Press.

Habermas, J. 1989. Problemas de legitimación en el capitalismo tardio. Madrid: Cátedra. Heller, A. 1978. Teoría de las necesidades en Marx. Barcelona: Península.

Hochfeld, J. 1963. Studia o marksowskiej teorii spoleczeństwa. Warsawa: Wydawnictwo Naukowe PWN.

Kolakowski, L. 1966. The Alienation of Reason: A History of Positivist Thought. Nueva York: Doubleday.

Kolakowski, L. 1972. Positivist Philosophy from Hume to the Vienna Circle. Londres: Pelican Books.

Lagerlof, N.-P. 2002. The Roads to and from Serfdom. Documento de trabajo. Montreal: Departamento de Economía, Universidad de Concordia.

Malewski, A. y Topolski J. 1960. Studia z metologii historii. Warsawa: Panstwowe Wydawnictwo Naukowe.

Marcuse, H. 1965. Eros y civilización. Ciudad de México: Joaquín Moritz.

Miliband, R. 1990. Réplica a Nicos Poulantzas. H. Tarcus (Ed.). Debates sobre el Estado capitalista (pp. 91-103). Buenos Aires: Imago Mundi.

Miliband, R. 1991. El Estado en la sociedad capitalista. Ciudad de México: Imago Mundi. Nove, A. 1998. La economía del socialismo factible. Madrid: Siglo XXI Editores.

Nowak, S. 1960. Egalitarian Attitudes of Warsaw Students. American Sociological Review, (25), 219-31.

Nowak, S. 1974. Stanisław Ossowski as a Sociologist. Polish Sociological Bulletin, (1), 13-26.

O’Connor, J. 1981. La crisis fiscal del Estado. Barcelona: Península.

Offe, C. 1985. Disorganized Capitalism. Cambridge: MIT Press.

Olson, M. 1992. La lógica de la acción colectiva. Bienes públicos y la teoría de grupos. Ciudad de México: Noriega Editores.

Ossowski, M. 1986. Bourgeois Morality. Londres: Routledge, Kegan Paul.

Ossowski, M. 1971. Social Determinants of Moral Ideas. Londres: Routledge, Kegan Paul.

Ossowski, S. 1972. Estructura de clases y conciencia social. Buenos Aires: Editorial Diez.

Pontusson, J. 2004. The Limits of Social Democracy: Investment Politics in Sweden. Ithaca, Nueva York: Cornell University Press.

Poulantzas, N. 1978. Poder politico y clases sociales en el Estado capitalista. Ciudad de México: Siglo XXI Editores.

Poulantzas, N. 1990. El problema del Estado capitalista. H. Tarcus (Ed.). Debates sobre el Estado capitalista (pp. 71-90). Buenos Aires: Imago Mundi 
Przeworski, A. 1988. Capitalismo y socialdemocracia. Madrid: Alianza Editorial.

Przeworski, A. 1990. The State and the Economy Under Capitalism. Oxford: Routledge.

Przeworski, A. 2003. States and Markets: A Primer in Political Economy. Nueva York: Cambridge University Press.

Przeworski, A. 1986. Intereses materiales, compromiso de clase y la transición al socialismo. Roemer, J. (Ed.). El marxismo: una perspectiva analítica. Ciudad de México: Fondo de Cultura Económica.

Przeworski, A. 2019. Crises of Democracy. Nueva York: Cambridge University Press.

Przeworski, A. y Wallerstein, M. 1988. Structural Dependence of the State on Capital. American Political Science Review, (82), 11-30.

Roemer, J. 1989. Teoría general de la explotación y de las clases. Madrid: Siglo XXI Editores.

Roemer, J. (Ed.). 1986. El marxismo: una perspectiva analítica. Ciudad de México: Fondo de Cultura Económica.

Roemer, J. 2020. What Is Socialism Today? Conceptions of a Cooperative Economy. Cowles Foundation Discussion Paper 2220.

Shapiro, C. y Stiglitz, J. 1986. Equilibrium Unemployment as a Worker Disciplining Device. American Economic Review, (74), 433-444.

Ward, B. 1957. The Firm in Illyria: Market Syndicalism. American Economic Review, (48), 566-589.

Wesołowski, W. 1979. Classes, Strata and Power (RLE Social Theory). Londres: Routledge.

Wiatr. 1961. Elections and Voting Behavior in Poland. En A. Ranney (Ed.). Behavioural Study of Politics. Urbana: University of Illinois Press.

\section{Obras citadas de Karl Marx}

1844. Sobre la cuestión judía. https://bit.ly/3yjnlBy

1844[1968]. Manuscritos: economía y filosofía. Madrid: Alianza Editorial.

1845[1967]. La sagrada familia. Ciudad de México: Grijalbo.

1845[1970]. La ideología alemana. Ciudad de México: Grijalbo.

1847[2004]. Miseria de la filosofía. Santiago de Chile, Madrid: EDAF.

1847[1980]. Trabajo asalariado y capital. En Obras escogidas (3 vols.). Moscú: Editorial

Progreso.

1848. Manifiesto del Partido Comunista (múltiples ediciones).

1850[2015]. Las luchas de clases en Francia, 1848 a 1850. Madrid: Fundación Federico

Engels. 
274 | Discursos Del Sur / ADAM PrZZworsKI

1852[2003]. El 18 brumario de Luis Bonaparte. Madrid: Fundación Federico Engels.

Citado en texto como 18 brumario.

1857-8[1973]. Elementos fundamentales para la crítica de la economía política [Grundrisse]. Ciudad de México: Siglo XXI Editores.

1859[1980]. Contribución a la crítica de la economía política. Ciudad de México: Siglo XXI Editores.

1867[2008]. El capital: crítica de la economía política (3 vols.). Ciudad de México: Siglo XXI Editores.

1871. Writings on Paris Commune (editado por Hal Draper). Nueva York: International Publishers. 